\title{
Simple Sequence Repeat (SSR) Markers for Genetic Mapping of Raspberry and Blackberry
}

\author{
Eric T. Stafne and John R. Clark \\ Department of Horticulture, University of Arkansas, Fayetteville, AR 72701
}

Courtney A. Weber

Department of Horticultural Sciences, New York State Agricultural Experiment Station, Cornell University, Geneva, NY 14456

Julie Graham

Scottish Crop Research Institute, Invergowrie, Dundee, Scotland DD2 5DA, UK

Kim S. Lewers ${ }^{1}$

USDA-ARS Fruit Laboratory, 10300 Baltimore Avenue, BARC-West Building O10A, Beltsville, MD 20705

\begin{abstract}
AdDitional INDEX words. Fragaria, Rosa, Rubus alceifolius, Rubus idaeus, Rubus occidentalis, Rubus subgenus Rubus
ABSTRACT. Interest in molecular markers and genetic maps is growing among researchers developing new cultivars of Rubus L. (raspberry and blackberry). Several traits of interest fail to express in seedlings or reliably in some environments and are candidates for marker-assisted selection. A growing number of simple sequence repeat (SSR) molecular markers derived from Rubus and Fragaria L. (strawberry) are available for use with Rubus mapping populations. The objectives of this study were to test 142 of these SSR markers to screen raspberry and blackberry parental genotypes for potential use in existing mapping populations that segregate for traits of interest, determine the extent of inter-species and inter-genera transferability with amplification, and determine the level of polymorphism among the parents. Up to 32 of the SSR primer pairs tested may be useful for genetic mapping in both the blackberry population and at least one of the raspberry populations. The maximum number of SSR primer pairs found useable for mapping was 60 for the raspberry population and $\mathbf{4 5}$ for the blackberry population. Acquisition of many more nucleotide sequences from red raspberry, black raspberry, and blackberry are required to develop useful molecular markers and genetic maps for these species. Rubus, family Rosaceae, is a highly diverse genus that contains hundreds of heterozygous species. The family is one of the most agronomically important plant families in temperate regions of the world, although they also occur in tropical and arctic regions as well. The most important commercial subgenus of Rubus is Idaeobatus Focke, the raspberries, which are primarily diploids. This subgenus contains the european red raspberry $R$. idaeus ssp. idaeus $\mathrm{L}$., as well as the american black raspberry $R$. occidentalis $L$. and the american red raspberry $R$. idaeus ssp. strigosus Michx. Interspecific hybridization of these, and other raspberry species, has led to greater genetic diversity and allowed for the introgression of superior traits such as large fruit size, fruit firmness and quality, disease resistance, and winter hardiness.
\end{abstract}

Blackberries reside in the subgenus Rubus (formerly Eubatus Focke). Modern eastern North American blackberry cultivars are comprised of many species, including $R$. allegheniensis Porter, $R$. argutus Link., $R$. cuneifolius Pursh., $R$. frondosus Bigel., $R$. rubrisetus Rydb. (=R. trivialis L.), and $R$. pergratus Blanch., as well as european blackberry species such as $R$. ulmifolius var. inermis Focke, $R$. thyrsiger Banning and Focke, and $R$. procerus P.J. Muell. Blackberry is a highly heterozygous plant and many current cultivars are tetraploid. Interest in development of molecular markers and maps has been limited, because of the varied reproductive strategies [sexual, facultatively apomictic,

Received for publication 30 Dec. 2004. Accepted for publication 1 Mar. 2005. The authors wish to thank Ms. Kate Rappaport for SSR testing reactions and Ms. Tina Sphon for reaction analyses. Thanks also to Dr. Tad Sonstagard for managing, and to the Beltsville Area Research Center for supporting the genotyping facility. Thanks also go to the North American Bramble Growers' Association for partial funding of this research. The authors also wish to thank Drs. Jim Ballington, Lisa J. Rowland, and Freddi Hammerschlag plus the anonymous reviewers for their helpful comments. Mention of trade names or commercial products in this publication is solely for the purpose of providing specific information and does not imply recommendation or endorsement by the Univ. of Arkansas, Cornell Univ., the Scottish Crops Research Inst., or the U.S. Dept. of Agriculture.

'To whom reprint requests should be addressed. E-mail: lewersk@ba.ars.usda. gov. and obligately apomictic (Hall, 1990)], cytological conditions (auto- and allo-polyploidy), and inheritance strategies (disomic and tetrasomic) (Lopez-Medina et al., 2000) of polyploid blackberries. Also, polyploid plants often display problems with reproducibility and amplification in polymerase chain reactions (PCR) (Buteler et al., 1999; Diwan et al., 1997; Röder et al., 1995). However, because eastern north american blackberries for the most part are not apomictic (Hall, 1990), sexual recombination can be assumed. Although alloploidy in Rubus is more common than autoploidy (Ourecky, 1975), various degrees of meiotic irregularity occur in north american species, and the high percentage of multivalents observed in tetraploid species suggests that both auto- and allopolyploidy are involved (Einset, 1947). The desire to incorporate relatively new and exciting traits of commercial importance such as thornlessness and fruit production on first-year canes (primocane fruiting) has led to greater interest in molecular marker analysis in blackberries.

Simple sequence repeat (SSR) markers are repeats of short nucleotide sequences, usually equal to or less than six bases in length, that vary in number (Rafalski et al., 1996). SSR markers have become quite useful in various aspects of molecular genetic studies in the past decade, including assessment of genetic diversity (Amsellem et al., 2001; Ashley et al., 2003), 
fingerprinting (Rongwen et al., 1995), ecological-genetic studies (Li et al., 2000), marker-assisted selection (Fazio et al., 2003), gene flow characterization (Aldrich and Hamrick, 1998; Chase et al., 1996), and genetic linkage mapping (Akkaya et al., 1995; Broun and Tanksley, 1996). They are desirable because they are often codominant, highly reproducible, frequent in most eukaryotes, and reveal high allelic diversity (Mohan et al., 1997). SSR markers are amplified using the PCR, thus allowing for the rapid generation of data from a relatively small amount of plant tissue. However, SSR markers are also expensive to generate and can be very laborious in certain species. Because of these expense and labor issues, many researchers have attempted to use SSR primers developed from one species for studies on related species and genera. Several studies have indicated successful inter-species and inter-genera results within Rosaceae (Ashley et al., 2003; Cipriani et al., 1999; Decroocq et al., 2003; Dirlewanger et al., 2002; Graham et al., 2002; Lewers et al., 2005) and other plant families (Bowers et al., 1996; Cordeiro et al., 2001; Decroocq et al., 2003; Echt et al., 1999; Guilford et al., 1997; Huang et al., 1998; Kijas et al., 1997; Selvi et al., 2003; Sharon et al., 1997).

One objective of this study was to utilize SSR markers developed from red raspberry [R. idaeus ssp. idaeus 'Glen Moy'(Graham et al., 2002, 2004)], wild bramble [R. alceifolius Poir (Amsellem et al., 2001)], and strawberry [F. ×ananassa Duschene ex Rozier 'Earliglow' (Lewers et al., 2005); F. virginiana Mill. (Ashley et al., 2003); and Fragaria vesca L. (James et al., 2003)] to screen raspberry and blackberry parental genotypes for potential use in mapping populations that segregate for important traits of interest and determine the level of polymorphism among the parents. A second objective was to determine the extent of inter-species and inter-genera transferability with amplification. Success in this area would circumvent the need for further creation of SSR markers specific to black raspberry and blackberry, thus greatly reducing SSR marker-development expenditures and allowing genetic mapping using non-species-specific SSR markers.

\section{Materials and Methods}

DESCRIPTION OF MAPPING POPULATIONS. A black raspberry $\times$ red raspberry cross of 'Jewel' $\times$ NY322 was made to create an interspecific hybrid that allows for the development of a map of each parent, and thus each species, in the $\mathrm{F}_{1}$ generation. There is no recombination in the $F_{1}$ between the two genomes and the heterozygosity of each parent can be mapped. The $\mathrm{F}_{1}$ population segregates for primocane fruiting, root production of adventitious shoots (suckering), tip rooting, and other important traits that would be good candidates for marker-assisted selection in a raspberry breeding program. An $\mathrm{F}_{2}$ population can then be used to join the maps based on recombination in that generation. SSR markers have proven successful in similar studies in the past (Lorieux et al., 2000). The breeding selection NY322 also carries a recessive allele for yellow fruit color that can be mapped in the $\mathrm{F}_{2}$ population.

The blackberry $\times$ blackberry cross of 'APF-12' $\left(\right.$ Prime-Jim $^{\mathrm{TM}}$ ) $\times$ 'Arapaho' was made to produce $F_{1}$ progeny that segregate for primocane fruiting, thornlessness, and other traits. Release of the first commercial primocane-fruiting blackberry cultivar (Clark et al., 2004) increased the importance of understanding more about the inheritance and location of the trait within the blackberry genome. Primocane fruiting does not always express in the first year and, therefore, is a good candidate for markerassisted selection. Previous work has indicated that the trait is qualitative, recessive, and segregates as would be expected in an autotetraploid (Lopez-Medina et al., 2000).

DESCRIPTION OF SSR PRIMER PAIRS. SSR primers tested for utility in the raspberry and blackberry mapping populations included 84 primer pairs derived from the spineless red raspberry 'Glen Moy' released by the Scottish Crops Research Institute in 1981 (Graham et al., 2002, 2004). As with many raspberry cultivars, the pedigree of 'Glen Moy' is complex and includes $R$. idaeus ssp. idaeus, R. occidentalis, and $R$. ideaus ssp. strigosus (Daubney, 1997), and SSR primer pairs derived from 'Glen Moy' sequence should reflect to some extent the species in its pedigree. Eight other Rubus-derived SSR primer pairs came from $R$. alceifolius Poir., a European weed (Amsellem et al., 2001). Because Rubus is classified in the same subfamily (Rosoideae) as Fragaria (strawberry), 57 strawberry-derived SSR primer pairs also were tested. A total of 39 SSR primer pairs came from genomic and expressed sequence tags (ESTs) from $F$. ×ananassa, cultivated strawberry (Lewers et al., 2005); four SSR primer pairs came from $F$. virginiana, the paternal progenitor of the cultivated strawberry (Ashley et al., 2003), and 14 SSR primer pairs came from the diploid F. vesca (James et al., 2003; Lewers et al., 2005).

PCR AND ELECTROPHORESIS. To determine how useful the primers would be for genetic mapping in Rubus, parents of the raspberry mapping population ('Jewel' and NY322) and the blackberry mapping population, ('Arapaho' and 'APF-12') were used in PCR to test the primer pairs' abilities to amplify a product and to detect polymorphisms. Young leaves were harvested from greenhouse- or field-grown plants, and DNA was extracted using a DNeasy Plant Maxi Kit (Qiagen, Valencia, Calif.). DNA was quantified using the Spectramax 190 spectrophotometer (Molecular Devices, Sunnyvale, Calif.), and diluted with $1 \times$ TE buffer to $30 \mathrm{ng} \cdot \mu \mathrm{L}^{-1}$. Dilutions to $0.03 \mathrm{ng} \cdot \mu \mathrm{L}^{-1}$ were made with $\mathrm{ddH}_{2} \mathrm{O}$.

To test if the primer pairs would amplify a product, unlabeled primers (Qiagen) were used in PCR. The reaction components included $1 \times$ PCR buffer with $1.5 \mathrm{mM} \mathrm{MgCl}_{2}$ (Qiagen), $0.67 \mathrm{~mm}$ dNTPs, $0.5 \mu$ M each primer, 0.4 U HotStarTaq polymerase enzyme (Qiagen), and template DNA at $0.002 \mathrm{ng} \cdot \mu \mathrm{L}^{-1}$ in a total reaction volume of $15 \mu \mathrm{L}$. An MJ Research Engine Tetrad with 96-well blocks (MJ Research, Waltham, Mass.) was used for amplification, heating reaction components to $95^{\circ} \mathrm{C}$ for $15 \mathrm{~min}$ to activate the polymerase, followed by 30 cycles of $40 \mathrm{~s}$ at $94{ }^{\circ} \mathrm{C}, 40 \mathrm{~s}$ at 52 ${ }^{\circ} \mathrm{C}$ or $59^{\circ} \mathrm{C}$, and $40 \mathrm{~s}$ at $72{ }^{\circ} \mathrm{C}$. A final 10 -min extension period at $72{ }^{\circ} \mathrm{C}$ was followed by storage at $4{ }^{\circ} \mathrm{C}$. PCR products $(5 \mu \mathrm{L})$ were added to water $(15 \mu \mathrm{L})$ and visualized after $12 \mathrm{~min}$ of electrophoresis through a $2 \%$ agarose gel using the E-gel 96 system (Invitrogen Corp., Carlsbad, Calif.). Gel images were captured in TIF files using an Alpha-Imager (Alpha Innotech Corp., San Leandro, Calif.), and analyzed with the E-gel 96 Editor software (Invitrogen).

To size the PCR products and identify size-polymorphisms, “poor man's" PCR reactions were used as described by Schuelke (2000). Three primers of unequal proportion are used in each reaction. The first 30 cycles use an annealing temperature specific to the genomic target sequence while the final eight cycles use a lower annealing temperature. The SSR primer pairs that amplified a product from any of the four parental genotypes were redesigned to incorporate a fluorescent protein into the amplification products. The M13 sequence, 5’TGTAAAACGACGGCCAGT3’ was added to the $5^{\prime}$ ends of the forward primers. For cost efficiency, M13 primers were labeled with the fluorescent proteins, FAM, VIC, NED, and PET (Applied Biosystems, Foster City, Calif.). Reaction components were assembled the same as for the unlabeled 
reactions, though three primers are used in each reaction: The redesigned forward primer, the reverse primer, and the fluorescently labeled M13 primer. The primer concentrations were in the proportions described by Schuelke (2000); the unlabeled reverse primer concentrations and the labeled M13 primer concentrations were equimolar at $0.5 \mu \mathrm{M}$, while the unlabeled chimeric forward primer concentration was one-fourth the molarity of the other two primers, $0.125 \mu \mathrm{M}$. The reaction components were heated the same as for the unlabeled reactions, but followed by eight cycles of $40 \mathrm{~s}$ at $94{ }^{\circ} \mathrm{C}, 40 \mathrm{~s}$ at $52{ }^{\circ} \mathrm{C}$, and $40 \mathrm{~s}$ at $72{ }^{\circ} \mathrm{C}$ to incorporate the fluorescently labeled M13 primer, and the final 10 min extension period at $72{ }^{\circ} \mathrm{C}$ and storage at $4{ }^{\circ} \mathrm{C}$. Fluorescently labeled PCR products were separated by capillary gel electrophoresis and detected using the Applied Biosystems, 3730 DNAAnalyzer. The size standard used during electrophoresis was GENESCAN 500HD (LIZ). Sizing data were analyzed using the Applied Biosystems Genemapper software.

\section{Results}

A total of 142 unique SSR primer pairs were used in PCR amplifications with the four Rubus genotypes (Table 1); seven pairs of the raspberry-derived SSR primer pairs were identical. The percentages of 'Glen Moy' red raspberry-derived SSR primer pairs that amplified a product were $65 \%$ for red raspberry selection NY322, 47\% for black raspberry 'Jewel', 29\% for blackberry 'APF-12', and 30\% for blackberry 'Arapaho'. Likewise, 32\% and $27 \%$ of the strawberry-derived SSR primer pairs amplified a product from blackberry 'APF-12' and 'Arapaho', respectively. Of the eight SSR primer pairs derived from $R$. alceifolius, two $(25 \%)$ amplified products from all four parents. This was slightly less than the percentage of raspberry- or strawberry-derived primer pairs that amplified products from the blackberry parents. Only $12 \%$ of the strawberry-derived SSR primer pairs amplified a product from either NY322 or 'Jewel' raspberry.

Our findings indicate that 51 raspberry-derived SSR primer pairs, two $R$. alceifolius SSR primer pairs, and seven strawberryderived SSR primer pairs, for a total of 60 SSR primer pairs are available for genetic mapping in the raspberry population. Twenty-six of the raspberry-derived SSR primer pairs, both of the $R$. alceifolius SSR primer pairs, and one of the strawberryderived SSR primer pairs, for a total of 29 SSR primer pairs detected product size differences between NY322 and 'Jewel'. Sixteen of the raspberry-derived SSR primer pairs amplified a product from one parent but not the other. Nine raspberry-derived SSR primer pairs and six more strawberry-derived SSR primer pairs amplified monomorphic products from the raspberry parents. These 15 SSR primer pairs may be useful for mapping in the $F_{2}$ population since the $F_{1}$ individual used to generate the $F_{2}$ population may be heterozygous at several loci.

Twenty-four raspberry-derived SSR primer pairs, both the $R$. alceifolius SSR, and 19 strawberry-derived SSR primer pairs, for a total of 45 SSR primer pairs are available for genetic mapping in the blackberry population. Fourteen of the raspberry-derived SSR primer pairs, one of the $R$. alceifolius SSR primer pairs, and four of the strawberry-derived SSR primer pairs, for a total of 19 SSR primer pair, detected base-pair differences between 'APF-12' and 'Arapaho'. Three of the raspberry-derived SSR primer pairs and three of the strawberry-derived SSR primer pairs amplified a product from one but not the other parent. Seven raspberry-derived SSR primer pairs, one $R$. alceifolius SSR, and 12 strawberry-derived SSR primer pairs amplified monomorphic products from the blackberry parents. These 20 SSR primer pairs may be useful for mapping since blackberry is highly heterozygous and is autotetrasomic (Lopez-Medina et al., 2000).

Notably, a total of 32 SSR primer pairs are available for genetic mapping in these raspberry and blackberry populations, 23 derived from raspberry, two from $R$. alceifolius SSR, and seven from strawberry. Of these, 22 detected product size polymorphisms between at least one set of population parents, and 10, mostly raspberry-derived, detected polymorphisms between both sets. Twenty SSRs amplified monomorphic products between at least one set of parents, and seven of these, mainly from strawberry, amplified monomorphic products in both sets.

\section{Discussion}

A useful number of SSR primer pairs derived from red raspberry 'Glen Moy' amplified a product from the parents of the raspberry populations, but the percentage was much lower than what has been reported among strawberry species (Ashley et al., 2003; Lewers et al., 2005). The genetic background of 'Glen Moy' is quite diverse, but $>80 \% R$. idaeus ssp. idaeus with the remainder made up of $12 \% R$. idaeus ssp. strigosus and $2 \% R$. occidentalis (Dale et al., 1993). Of the raspberry genotypes tested, NY322 is comprised of more than $52 \%$ R. idaeus ssp. idaeus, however, it also has significantly more $R$. idaeus ssp. strigosus than does 'Glen Moy'. Nearly 29\% of NY322 is from R. idaeus ssp. strigosus-based genetic material. In addition to those two species, $R$. pungens oldhamii Miq. and $R$. chamaemorus L. are also present in its background (Dale et al., 1993). The large disparity in the amount of non- $R$. idaeus ssp. idaeus genes between 'Glen Moy' and NY322 could account for the lower percentage of useful SSR primer pairs. Also, only three founding clones are shared between the two genotypes, including 'Lloyd George', 'Newman', and 'Herbert'. NY322 and 'Glen Moy' have roughly equal amounts of 'Lloyd George' and 'Herbert' in their respective backgrounds, but NY322 has much more genetic material donated from 'Newman'.

Howarth et al. (1997) found 99\% sequence identity between $R$. idaeus ssp. idaeus and $R$. idaeus ssp. strigosus for the $n d h \mathrm{~F}$ gene and stated that $R$. idaeus ssp. idaeus formed a cohesive group with $R$. idaeus ssp. strigosus and another North American subspecies [R. melanolasius (Dieck) Focke]. That study was based on a very specific region of chloroplast DNA and may not be variable enough to gauge the diversity of Rubus species and subspecies. However, a separate study conducted by Moore (1993) showed that cultivars could be placed into distinct groupings based on species background for chloroplast DNA. The R. idaeus ssp. strigosus cultivar Dalhousie Lake 4 comprised a group unto itself based on banding patterns. It was more closely related to the $R$. idaeus groups than to the $R$. occidentalis groups. Waugh et al. (1990) found no differences in chloroplast DNA among $R$. idaeus ssp. idaeus genotypes and Moore (1993) found few differences, suggesting that there is little chloroplast DNA variability within $R$. idaeus ssp. idaeus, but both stated that nuclear DNA might be more sensitive to variation.

A study by Graham and McNicol (1995) using random amplified polymorphic DNA(RAPD) markers found that $R$. idaeus ssp. idaeus clones clustered differently from those of $R$. occidentalis. One $R$. idaeus ssp. strigosus clone ('Latham') was included and clustered with the $R$. idaeus ssp. idaeus genotypes, but was the most distinct of the red raspberry group. Overall, $R$. occidentalis had a low similarity index when compared to both $R$. idaeus ssp. 
Table 1. Previously published simple sequence repeat molecular markers (SSRs) tested in polymerase chain reactions (PCR) with template DNA extracted from parents of Rubus (raspberry and blackberry) genetic mapping populations to determine potential utility for genetic mapping within the populations. A total of 142 SSR primer pairs from the cited manuscripts were tested, and those not in this table did not amplify a product in a minimum of four attempts. Breeding selection NY322 ( $R$. idaeus, red raspberry) and 'Jewel' ( $R$. occidentalis, black raspberry) were used to derive an $\mathrm{F}_{1}$ and an $\mathrm{F}_{2}$ population. 'Arapaho' (Rubus spp., blackberry) and 'APF-12' ( $R$. spp., blackberry) also were used to derive an $\mathrm{F}_{1}$ population.

\begin{tabular}{|c|c|c|c|c|c|c|}
\hline SSR primer pair ${ }^{z}$ & $\begin{array}{l}\text { NY322 PCR } \\
\text { product size }\end{array}$ & $\begin{array}{l}\text { ‘Jewel’ PCR } \\
\text { product size }\end{array}$ & $\begin{array}{c}\text { Type or } \\
\text { presence of } \\
\text { polymorphism }\end{array}$ & $\begin{array}{l}\text { 'Arapaho' PCR } \\
\text { product size }\end{array}$ & $\begin{array}{l}\text { ‘APF-12' PCR } \\
\text { product size }\end{array}$ & $\begin{array}{c}\text { Type or } \\
\text { presence of } \\
\text { polymorphism }\end{array}$ \\
\hline \multicolumn{7}{|c|}{ Derived from Rubus species hybrid red raspberry 'Glen Moy' (Graham et al., 2002, 2004) } \\
\hline Rubus 262 and Rubus $262 b$ & 242 & 220 & product size & $219 / 225 / 266$ & $219 / 225 / 261$ & product size \\
\hline Rubus 277 and Rubus $277 \mathrm{a}$ & 250 & 250 & monomorphic & $215 / 269 / 281$ & $207 / 269 / 281$ & product size \\
\hline Rubus 26 and Rubus 26a & $107 / 138$ & 138 & product size & none & none & none \\
\hline Rubus126 and Rubus 126b & 215 & $155 / 165$ & product size & none & none & none \\
\hline Rubus 223 and Rubus 223a & 171 & $121 / 155$ & product size & none & none & none \\
\hline Rubus 280 and Rubus 260a & 165 & none & amplification & none & none & none \\
\hline Rubus $2 \mathrm{a}$ & $174 / 182 / 193$ & 182 & product size & $179 / 214$ & $179 / 214$ & monomorphic \\
\hline Rubus 6a & 150 & 150 & monomorphic & none & none & none \\
\hline Rubus12a & 160 & 141 & product size & 247/291/302/339 & $229 / 247 / 302 / 345$ & product size \\
\hline Rubus16a & 169 & 169 & monomorphic & 164 & none & amplification \\
\hline Rubus 22a & $134 / 169$ & $126 / 134 / 169$ & product size & none & none & none \\
\hline Rubus 24a & 184 & none & amplification & 133 & $133 / 168$ & product size \\
\hline Rubus 25a & $163 / 173$ & 173 & product size & none & none & none \\
\hline Rubus 35a & $229 / 239$ & 256 & product size & none & none & none \\
\hline Rubus 43a & 226 & 226 & monomorphic & $219 / 227$ & $212 / 219 / 227$ & product size \\
\hline Rubus $45 c$ & none & none & none & 184 & none & amplification \\
\hline Rubus 47a & 232 & none & amplification & $217 / 238 / 248$ & $217 / 238 / 248$ & monomorphic \\
\hline Rubus 57a & 191 & none & amplification & none & none & none \\
\hline Rubus 59b & $220 / 259$ & none & amplification & none & none & none \\
\hline Rubus 98d & 198 & 198 & monomorphic & none & none & none \\
\hline Rubus $102 \mathrm{c}$ & 137 & 137 & monomorphic & none & 137 & amplification \\
\hline Rubus 105b & $165 / 173 / 181$ & 165 & product size & $171 / 173$ & 175 & product size \\
\hline Rubus 107a & $172 / 179$ & 179 & product size & $190 / 195$ & 190 & product size \\
\hline Rubus 110a & $176 / 194$ & $186 / 201$ & product size & 203 & 203 & monomorphic \\
\hline Rubus 116a & 299 & none & amplification & none & none & none \\
\hline Rubus $117 \mathrm{~b}$ & $132 / 134 / 158$ & $132 / 147 / 153 / 273$ & product size & $127 / 147 / 162$ & $127 / 151 / 162$ & product size \\
\hline Rubus $118 b$ & $129 / 180$ & none & amplification & none & none & none \\
\hline Rubus 119a & 157 & $157 / 176$ & product size & 157 & 157 & monomorphic \\
\hline Rubus $123 \mathrm{a}$ & $158 / 168$ & $158 / 172$ & product size & none & none & none \\
\hline Rubus $137 \mathrm{a}$ & 198 & none & amplification & none & none & none \\
\hline Rubus $145 a$ & 152 & 152 & monomorphic & $150 / 154$ & $145 / 150$ & product size \\
\hline Rubus 160a & 173 & 179 & product size & none & none & none \\
\hline Rubus $167 \mathrm{a}$ & 198 & 178 & product size & none & none & none \\
\hline Rubus 194h & $200 / 202$ & $143 / 145$ & product size & $127 / 154$ & 127 & product size \\
\hline Rubus 210a & $122 / 130$ & none & amplification & none & none & none \\
\hline Rubus 228a & $159 / 161 / 163 / 165$ & $142 / 149$ & product size & none & none & none \\
\hline Rubus $237 \mathrm{~b}$ & 160 & 157 & product size & 153 & 157 & product size \\
\hline Rubus 251a and Rubus 270a & $182 / 206$ & 182 & product size & $197 / 206$ & 206 & product size \\
\hline Rubus 253a & $170 / 191$ & none & amplification & none & none & none \\
\hline Rubus 256e & 209 & 167 & product size & none & none & none \\
\hline Rubus 257a & 203 & 207 & product size & none & none & none \\
\hline Rubus 259f & 265 & 257 & product size & 261 & 261 & monomorphic \\
\hline Rubus 263f & none & 254 & amplification & none & none & none \\
\hline Rubus 264b & 193 & none & amplification & none & none & none \\
\hline Rubus $268 b$ & $204 / 226$ & 204 & product size & none & none & none \\
\hline Rubus 275a & 161 & 161 & monomorphic & $182 / 206$ & $140 / 172 / 182$ & product size \\
\hline Rubus 285a & $188 / 205$ & none & amplification & $196 / 217 / 240$ & $196 / 232$ & product size \\
\hline Rubus 289a & 150 & none & amplification & none & none & none \\
\hline RubfruitE4 & 182 & 182 & monomorphic & 182 & 182 & monomorphic \\
\hline RubfruitC1 & 172 & $177 / 180$ & product size & 172 & 172 & monomorphic \\
\hline Rubleaf86 & $253 / 255$ & none & amplification & none & none & none \\
\hline Rubleaf97 & 222 & none & amplification & none & none & none \\
\hline
\end{tabular}


Table 1. Continued.

\begin{tabular}{|c|c|c|c|c|c|c|}
\hline SSR primer pairz & $\begin{array}{l}\text { NY322 PCR } \\
\text { product size }\end{array}$ & $\begin{array}{l}\text { ‘Jewel' PCR } \\
\text { product size }\end{array}$ & $\begin{array}{c}\text { Type or } \\
\text { presence of } \\
\text { polymorphism }\end{array}$ & $\begin{array}{c}\text { ‘Arapaho' PCR } \\
\text { product size }\end{array}$ & $\begin{array}{l}\text { ‘APF-12' PCR } \\
\text { product size }\end{array}$ & $\begin{array}{c}\text { Type or } \\
\text { presence of } \\
\text { polymorphism }\end{array}$ \\
\hline \multicolumn{7}{|c|}{ Derived from Rubus alceifolius bramble (Amsellem et al., 2001) } \\
\hline mRaCIRRI1D3 & 217 & $195 / 212$ & product size & 213 & 213 & monomorphic \\
\hline mRaCIRRIV2A8 & $209 / 229$ & $216 / 223$ & product size & $218 / 223 / 228$ & $198 / 218 / 223$ & product size \\
\hline \multicolumn{7}{|c|}{ Derived from Fragaria $\times$ ananassa strawberry (Lewers et al., 2005) } \\
\hline ARSFL_4 & none & none & none & 171 & 171 & monomorphic \\
\hline ARSFL_7 & 202 & 202 & monomorphic & 202 & 202 & monomorphic \\
\hline ARSFL_9 & $118 / 198 / 210 / 238$ & $188 / 198 / 210$ & product size & $219 / 228 / 234 / 242$ & $208 / 222 / 225 / 239$ & product size \\
\hline ARSFL_10 & none & none & none & 267 & $161 / 242$ & product size \\
\hline ARSFL_11 & none & none & none & 255 & 255 & monomorphic \\
\hline ARSFL_13 & none & none & none & none & 185 & amplification \\
\hline ARSFL_22 & none & none & none & $183 / 187$ & $183 / 187$ & monomorphic \\
\hline ARSFL_23 & none & none & none & $165 / 171$ & 168 & product size \\
\hline ARSFL_30 & 174 & 174 & monomorphic & $174 / 178$ & $174 / 178$ & monomorphic \\
\hline ARSFL_34 & none & none & none & 327 & 327 & monomorphic \\
\hline ARSFL_97 & none & none & none & 184 & 184 & monomorphic \\
\hline ARSFL_104 & 198 & 198 & monomorphic & 200 & 200 & monomorphic \\
\hline ARSFL_133 & 204 & 204 & monomorphic & $189 / 204$ & $189 / 204$ & monomorphic \\
\hline ARSFL_134 & $182 / 232$ & $182 / 232$ & monomorphic & $182 / 232$ & $182 / 232$ & monomorphic \\
\hline \multicolumn{7}{|c|}{ Derived from Fragaria virginiana strawberry (Ashley et al., 2003) } \\
\hline Fvi11 & none & none & none & none & 142 & amplification \\
\hline Fvi20 & 132 & 132 & monomorphic & 132 & 132 & monomorphic \\
\hline \multicolumn{7}{|c|}{ Derived from Fragaria vesca strawberry (James et al., 2003) } \\
\hline EMFv4 & none & none & none & $242 / 260 / 302 / 365$ & $220 / 260 / 365$ & monomorphic \\
\hline EMFv8 & none & none & none & $265 / 317$ & $165 / 213$ & product size \\
\hline EMFv9 & none & none & none & none & $218 / 224$ & amplification \\
\hline
\end{tabular}

zIf two SSR primer pairs are listed together on a line, we found their sequences were identical.

idaeus 'Glen Moy' and R. idaeus ssp. strigosus 'Latham' (39\% and $42 \%$, respectively). 'Latham' was more similar to 'Glen Moy' (53\%) than to $R$. occidentalis in that study, however, a previous experiment (Graham et al., 1994) showed less similarity (40\%) between the two cultivars. Trople and Moore (1999) found that $R$. occidentalis was not closely related to either $R$. idaeus ssp. strigosus or $R$. idaeus ssp. idaeus based on similarity values derived from RAPDs (31\% to 35\%). Yet two R. idaeus ssp. idaeus cultivars, Meeker and Tulameen, had a high genetic similarity of $77 \%$. The R. idaeus ssp. strigosus cultivar Dalhousie Lake 4 was only slightly more similar to the R. idaeus ssp. idaeus cultivars (40\% to $45 \%)$.

As for 'Jewel', a black raspberry totally derived from $R$. occidentalis (Ourecky and Slate, 1973), it seems that 47\% amplification using 'Glen Moy' SSR primer pairs is better than could be expected, especially since 'Glen Moy' only has $2 \% R$. occidentalis in its background (through 'Cumberland'). This result reveals that the use of cross-species SSR primer pairs is possible within Rubus, although not as successful as in other genera such as Fragaria (Ashley et al., 2003; Lewers et al., 2005).

Only one of the eight SSR primer pairs from $R$. alceifolius detected a size polymorphism for NY322 and 'Jewel.' Another SSR was monomorphic, thus only $25 \%$ of the SSR primer pairs from the wild bramble species $R$. alceifolius amplified any product. Rubus alceifolius is in the Rubus subgenus, Malachobatus Focke, which primarily occurs in Asia. The probable divergent evolution of this species contributed to the failure of most of the SSR markers. Rubus alceifolius is native to Southeast Asia and has been introduced to several areas where it has become a weed species. However, the derivation of the original SSR primer sequences was from plants from La Réunion, an island east of
Madagascar in the Indian Ocean. And although amplification was found with other species from the Rubus subgenera Idaeobatus and Malachobatus, none were tested on subgenus Rubus. Results from other studies (Pamfil et al., 2000; Trople and Moore, 1999) suggest that the Rubus subgenus is somewhat divergent from both Idaeobatus and Malachobatus. Cluster analysis has shown that genotypes in the subgenus Rubus form distinct clusters from Malachobatus and Idaeobatus, both of which cluster together (Pamfil et al., 2000). Genetic similarity studies found low percent similarity between species within subgenus Rubus and subgenus Idaeobatus (Trople and Moore, 1999).

Fewer than expected SSR primer pairs derived from the red raspberry 'Glen Moy' amplified a product from and revealed polymorphism between the blackberry genotypes. This may be attributable to the few shared species within their respective backgrounds. The only known species that is shared between 'Glen Moy' and 'Arapaho' and 'APF-12' is R. idaeus ssp. strigosus. 'Glen Moy' contains both 'Marlboro' and 'Herbert', both of which are comprised of R. idaeus ssp. strigosus. For both 'Arapaho' (Moore and Clark, 1993) and 'APF-12', R. idaeus ssp. strigosus was introduced through the cultivar Brazos via 'Nessberry', which resulted from a cross of $R$. trivialis and 'Brilliant' ( $R$. idaeus ssp. strigosus). Graham et al. (1994) reported in a study using RAPD markers that the cultivar Latham (derived from $R$. idaeus ssp. strigosus) displayed only $30 \%$ to $40 \%$ similarity to $R$. idaeus ssp. idaeus-derived raspberry cultivars. Another study by Trople and Moore (1999) revealed through a similarity index from RAPD markers that the $R$. idaeus ssp. idaeus-derived cultivars Meeker and Tulameen were $77 \%$ similar, whereas, when those two cultivars were compared to a $R$. idaeus ssp. strigosus genotype, that similarity percentage averaged only $43 \%$. 
'Glen Moy' is predominantly made up of $R$. idaeus ssp.idaeus, whereas the blackberry cultivars in this study are largely comprised of $R$. allegheniensis and $R$. argutus. In a study that compared sequence data from the internal transcribed spacer region (ITS) of nuclear ribosomal DNA, 'Arapaho' and 'APF-12' showed a genetic distance of $0-1 \%$ among other eastern north american blackberry cultivars and species ( $R$. allegheniensis and $R$. argutus), but had $3 \%$ to $4 \%$ distance when compared to R. idaeus ssp. idaeus and 'Heritage', a red raspberry cultivar (Stafne et al., 2004). Other studies found similar results (Alice and Campbell, 1999; Howarth et al., 1997).

Of the eight primer pairs derived from $R$. alceifolius, only two were successful in amplifying a product for the blackberries, 'Arapaho' and 'APF-12'. Rubus alceifolius resides in the Rubus subgenus, Malachobatus, which Pamfil et al. (2000), using RAPD analysis, found to be in mostly distinct clusters, with only $R$. parvifolius L. (Idaeobatus) residing in the Malachobatus cluster. Three Malachobatus species were found in the Idaeobatus cluster (R. hayata-koidzumii Naruh., $R$. assamensis Focke, and $R$. tephrodes Hance). A study using AFLP markers by Amsellem et al. (2000) reported that a strong separation between Rubus subgenus Idaeobatus and subgenus Malachobatus was evident. They also surmised that the $R$. alceifolius plants, from which the SSR markers were derived, growing on La Réunion, reproduced entirely apomictically, thus resulting in monoclonality. This narrow range of genetic material from which the SSR markers were derived may have contributed to the poor results.

The low percentage success of strawberry-derived SSR markers for the raspberries and blackberries in this study underscores the possibility that cross-generic use of SSR markers may be limited (Lewers et al., 2005). Interestingly, successful intergeneric crosses between a tetraploid blackberry and an octoploid strawberry have been made (Naess et al., 1998), and resulted in a hexaploid plant. This result suggests that some genetic compatibility may exist for fertility, yet the plant had no hybrid characteristics and no difference in chromosome size (Naess et al., 1998). In addition, Lewers et al. (2005) reported that 30 Rosa-derived SSR primer pairs failed to amplify a single product from raspberry, blackberry or strawberry genotypes tested, including the four in this study, even though all belong in the subfamily Rosoideae. This is somewhat consistent with prior findings (Decroocq et al., 2003) that indicate limited inter-species transfer of SSR markers within the family Rosaceae. Decroocq et al. (2003) also reported that the threshold distance for amplification within Rosaceae is limited and that the optimal SSR markers were derived from closely related species within the same subgenus for apricot (Prunus armeniaca L.).

With a maximum number of SSR primer pairs potentially usable for mapping at only 60 for the raspberry population and only 45 for the blackberry population, there is a clear need for developing additional SSR primer pairs for genetic mapping in both populations. An effort currently is being made to develop more SSR primer pairs from 'Glen Moy' ESTs and genomic sequences. Multiple efforts also are underway to obtain blackberry genomic (N.V. Bassil, personal communication) and EST sequences for SSR development.

\section{Literature Cited}

Akkaya, M.S., R. Shoemaker, J.E. Specht, A.A. Bhagwat, and P.B. Cregan. 1995. Integration of simple sequence repeat (SSR) DNA markers into a soybean linkage map. Crop Sci. 35:1439-1445.

Aldrich, P.R. and J.L. Hamrick. 1998. Reproductive dominance of pasture trees in a fragmented tropical forest mosaic. Science 281:103-105.

Alice, L.A. and C.S. Campbell. 1999. Phylogeny of Rubus (Rosaceae) based on nuclear ribosomal DNA internal transcribed spacer region sequences. Amer. J. Bot. 86:81-97.

Amsellem L., C. Dutech, and N. Billotte. 2001. Isolation and characterization of polymorphic microsatellite loci in Rubus alceifolius Poir (Rosaceae), an invasive weed in La Reunion island. Mol. Ecol. Notes 1:33-35.

Amsellem, L., J.L. Noyer, T. Le Bourgeois, and M. Hossaert-McKey. 2000. Comparison of genetic diversity of the invasive weed Rubus alceifolius Poir. (Rosaceae) in its native range and in areas of introduction, using amplified fragment length polymorphism (AFLP) markers. Mol. Ecol. 9:443-455.

Ashley, M.V., J.A. Wilk, S.M.N. Styan, K.J. Craft, K.L. Jones, K.A. Feldheim, K.S. Lewers, and T.L. Ashman. 2003. High variability and disomic segregation of microsatellites in the octoploid Fragaria virginiana Mill (Rosaceae). Theor. Appl. Genet. 107:1201-1207.

Bowers, J.E., G.S. Dangl, R. Vignani, and C.P. Meredith. 1996. Isolation and characterization of new polymorphic simple sequence repeat loci in grape (Vitis vinifera L.). Genome 39:628-633.

Broun, P. and S.D. Tanksley. 1996. Characterization and genetic mapping of simple repeat sequences in the tomato genome. Mol. Gen. Genet. 250:39-49.

Buteler, M.I., R.L. Jarret, and D.R. LaBonte. 1999. Sequence characterization of microsatellites in diploid and polyploid Ipomoea. Theor. Appl. Genet. 99:123-132.

Chase, M.R., C. Moller, R. Kesseli, and K.S. Bawa. 1996. Distant gene flow in tropical trees. Nature 383:398-399.

Cirpriani, G., G. Lot, W.-G. Huang, M.T. Marrazzo, E. Peterlunger, and R. Testolin. 1999. AC/GT and AG/CT microsatellite repeats in peach [Prunus persica (L.) Batsch]: Isolation, characterisation, and crossspecies amplification in Prunus. Theor. Appl. Genet. 99:65-72.

Clark, J.R., J.N. Moore, and J. Lopez-Medina. 2004. Primocane-fruiting blackberry cultivar releases from the University of Arkansas. HortScience 39:662. (Abstr.)

Cordeiro, G.M., R. Casu, C.L. McIntyre, J.M. Manners, and R.J. Henry. 2001. Microsatellite markers from sugarcane (Saccharum spp.) ESTs cross transferable to erianthus and sorghum. Plant Sci. 160:1115-1123.

Dale, A., P.P. Moore, R.J. McNicol, T.M. Sjulin, and L.A. Burmistrov. 1993. Genetic diversity of red raspberry varieties throughout the world. J. Amer. Soc. Hort. Sci. 118:119-129.

Daubney, H. 1997. Raspberry, p. 635-662. In: ASHS Press (ed.). The Brooks and Olmo register of fruit and nut varieties. $3^{\text {rd }}$ ed. ASHS Press, Alexandria, Va.

Decroocq, V., M.G. Fave, L. Hagen, L. Bordenave, and S. Decroocq. 2003. Development and transferability of apricot and grape EST microsatellite markers across taxa. Theor. Appl. Genet. 106:912-922.

Dirlewanger, E., P. Crosson, M. Tavaud, M.J. Aranzana, C. Poizat, A. Zanetto, P. Arus, and F. Laigret. 2002. Development of microsatellite markers in peach [Prunus persica (L.) Batsch] and their use in genetic diversity analysis in peach and sweet cherry (Prunus avium L.). Theor. Appl. Genet. 105:127-138.

Diwan, N., A.A. Bhagwat, G.B. Bauchan, and P.B. Cregan. 1997. Simple sequence repeat DNA markers in alfalfa and perennial and annual Medicago species. Genome 40:887-895.

Echt, C.S., G.G. Vendramin, C.D. Nelson, and P. Marquardt. 1999. Microsatellite DNA as shared genetic markers among conifer species. Can. J. For. Res. 29:365-371.

Einset, J. 1947. Chromosome studies in Rubus. Gentes Herbarum 7:181-192. 
Fazio, G., S.M. Chung, and J.E. Staub. 2003. Comparative analysis of response to phenotypic and marker-assisted selection for multiple lateral branching in cucumber (Cucumis sativis L.). Theor. Appl. Genet. 107:875-883.

Graham, J. and R.J. McNicol. 1995. An examination of the ability of RAPD markers to determine the relationships within and between Rubus species. Theor. Appl. Genet. 90:1128-1132.

Graham, J., R.J. McNicol, K. Greig, and W.T.G. van de Ven. 1994. Identification of red raspberry cultivars and an assessment of their relatedness using fingerprints produced by random primers. HortScience 69:123-130.

Graham, J., K. Smith, K. MacKenzie, L. Jorgenson, C. Hackett, and W. Powell. 2004. The construction of a genetic linkage map of red raspberry (Rubus idaeus subsp. idaeus) based on AFLPs, genomic-SSR and EST-SSR markers. Theor. Appl. Genet. 109:740-749.

Graham, J., K. Smith, M. Woodhead, and J. Russell. 2002. Development and use of simple sequence repeat SSR markers in Rubus species. Mol. Ecol. Notes 2:250-252.

Guilford, P., S. Prakash, J.M. Zhu, E. Rikkerink, S. Gardiner, H. Bassett, and R. Forster. 1997. Microsatellites in Malus $\times$ domestica (apple): Abundance, polymorphism and cultivar identification. Theor. Appl. Genet. 94:249-254.

Hall, H.K. 1990. Blackberry breeding. Plant Breed. Rev. 8:249-312.

Howarth, D.G., D.E. Gardner, and C.W. Morden. 1997. Phylogeny of Rubus subgenus Idaeobatus (Rosaceae) and its implications toward colonization of the Hawaiian Islands. Syst. Bot. 22:433-441.

Huang, W.-G., G. Cipriani, M. Morgante, and R. Testolin. 1998. Microsatellite DNA in Actinidia chinensis: Isolation, characterisation, and homology in related species. Theor. Appl. Genet. 97:1269-1278.

James, C.M., F. Wilson, A.M. Hadonou, and K.R. Tobutt. 2003. Isolation and characterization of polyploid microsatellites in diploid strawberry (Fragaria vesca L.) for mapping, diversity studies and clone identification. Mol. Ecol. Notes 3:171-173.

Kijas, J.M.H., M.R. Thomas, J.C.S. Fowler, and M.L. Roose. 1997. Integration of trinucleotide microsatellites into a linkage map of Citrus. Theor. Appl. Genet. 94:701-706.

Lewers, K.S., S.M.N. Styan, S.C. Hokanson, and N.V. Bassil. 2005. Strawberry GenBank-derived and genomic simple sequence repeat (SSR) markers and their utility with strawberry, blackberry, and red and black raspberry. J. Amer. Soc. Hort. Sci. 130:102-115.

Li, Y., T. Fahima, A.B. Korol, J. Peng, M.S. Roder, V. Kirzhner, A. Beiles, and E. Nevo. 2000. Microsatellite diversity correlated with ecological-edaphic and genetic factors in three microsatellites of wild emmer wheat in north Israel. Mol. Biol. Evol. 17:851-862.

Lopez-Medina, J., J.N. Moore, and R.W. McNew. 2000. A proposed model for inheritance of primocane fruiting in tetraploid erect blackberry. $\mathrm{J}$. Amer. Soc. Hort. Sci. 125:217-221.
Lorieux, M., M.-N. Ndjiondjop, and A. Ghesquiere. 2000. A first interspecific Oryza sativa $\times$ Oryza glaberrima microsatellite-based genetic linkage map. Theor. Appl. Genet. 100:593-601.

Mohan, M., S. Nair, A. Bhagwat, T.G. Krishna, M. Yano, C.R. Bhatia, and T. Sasaki. 1997. Genome mapping, molecular markers and markerassisted selection in crop plants. Mol. Breed. 3:87-103.

Moore, P.P. 1993. Chloroplast DNA diversity in raspberry. J. Amer. Soc. Hort. Sci. 118:371-376.

Moore, J.N. and J.R. Clark. 1993. ‘Arapaho’ erect thornless blackberry. HortScience 28:861-862.

Naess, S.K., H.J. Swartz, and G.R. Bauchan. 1998. Ploidy reduction in blackberry. Euphytica 99:57-73.

Ourecky, D.K. 1975. Brambles, p. 98-129. In: J. Janick and J.N. Moore (eds.). Advances in fruit breeding. Purdue Univ. Press, West Lafayette, Ind.

Ourecky, D.K. and G.L. Slate. 1973. Jewel black raspberry. New York's Food and Life Sci. Bul. 35.

Pamfil, D., R.H. Zimmerman, S.K. Naess, and H.J. Swartz. 2000. Investigation of Rubus breeding anomalies and taxonomy using RAPD analysis. Small Fruits Rev. 1:43-56.

Rafalski, J.A., J.M. Vogel, M. Morgante, W. Powell, C. Andre, and S.V. Tingey. 1996. Generating and using DNA markers in plants, p. 75-134. In: B. Birren and E. Lai (eds.). Nonmammalian genomic analysis. A practical guide. Academic, San Diego.

Röder, M.S., J. Plaschke, S.U. Konig, A. Borner, M. Sorrells, S.D. Tanksley, and M.W. Ganal. 1995. Abundance, variability and chromosomal location of microsatellites in wheat. Mol. Gen. Genet. 246:327-333.

Rongwen, J., M.S. Akkaya, A.A. Bhagwat, U. Levi, and P.B. Cregan. 1995. The use of microsatellite DNA markers for soybean genotypes identification. Theor. Appl. Genet. 90:43-48.

Selvi, A., N.V. Nair, N. Balasundaram, and T. Mohapatra. 2003. Evaluation of maize microsatellite markers for genetic diversity analysis and fingerprinting in sugarcane. Genome 46:394-403.

Sharon, D., P.B. Cregan, S. Mhameed, M. Kusharska, J. Hillel, E. Lahav, and U. Lavi. 1997. An integrated genetic linkage map of avocado. Theor. Appl. Genet. 95:911-921.

Schuelke, M. 2000. An economic method for the fluorescent labeling of PCR fragments: A poor man's approach to genotyping for research and high-throughput diagnostics. Nature Biotech. 18:233-234.

Stafne, E.T., A.L. Szalanski, and J.R. Clark. 2004. Nuclear ribosomal ITS region sequences for differentiation of Rubus genotypes. J. Ark. Acad. Sci. 57:176-180.

Trople, D.D. and P.P. Moore. 1999. Taxonomic relationships in Rubus based on RAPD analysis. Acta. Hort. 505:373-378.

Waugh, R., W.T.G. van de Ven, M.S. Phillips, and W. Powell. 1990. Chloroplast DNA diversity in the genus Rubus (Rosaceae) revealed by Southern hybridization. Plant Syst. Evol. 172:65-75. 